Revista Estudios, (38), 2019.

Junio 2019-Noviembre 2019

ISSN 1659-3316

Mejía Flores José Francisco

\title{
Dossier
}

México y Centroamérica

\section{La Unión Democrática Centroamericana en México y su solidaridad con los republicanos españoles, 1943-1945}

José Francisco Mejía Flores Centro de Investigaciones sobre América Latina y El Caribe Universidad Nacional Autónoma de México (UNAM), México

mejiafr@unam.mx

https://orcid.org/0000-0002-3454-7499

Recibido: 30 de abril de 2019

Aceptado: 20 de mayo de 2019

Resumen: Las actividades de la Unión Democrática Centroamericana en México se enmarcan en la coyuntura del desarrollo de la Segunda Guerra Mundial, justo en el momento de la proyección de un probable triunfo aliado sobre el nazi fascismo. En este trabajo se analiza la solidaridad que la Unión Democrática Centroamericana manifestó a la causa de la República Española, en su lucha anti franquista hasta 1945.

Palabras Clave: Unión Democrática Centroamericana; República Española; Exilios; Centroamérica; España.

\section{The Central American Democratic Union in Mexico and its solidarity with the Spanish Republicans, 1943-1945}

Abstract: The activities of the Central American Democratic Union in Mexico are framed in the context of the development of World War II, just at the moment of the projection of a probable Allied triumph over Nazi fascism. This paper analyzes the solidarity that the Central American Democratic Union manifested to the cause of the Spanish Republic, in its anti-Franco struggle until 1945.

\section{(c) (i) (9) (2)}

La Revista Estudios es editada por la Universidad de Costa Rica y se distribuye bajo una Licencia Creative Commons Atribución-NoComercial-CompartirIgual 3.0 Costa Rica. Para más información envíe un mensaje a 
Revista Estudios, (38), 2019.

Junio 2019-Noviembre 2019

ISSN 1659-3316

Mejía Flores José Francisco

Key Words:Central American Democratic Union; Spanish Republic; Exiles; Central America; Spain.

\section{Presentación}

Bajo el influjo del preludio, el inicio, desarrollo y el desenlace de la Segunda Guerra Mundial (1939-1945), una gran parte de los sistemas políticos que se sostenían por diversas circunstancias se resquebrajaron debido a los cambios experimentados en la nueva geopolítica internacional. América Latina fue un buen ejemplo de ello y en Centroamérica de plano cayeron dos gobiernos: el de Maximiliano Hernández Martínez en El Salvador (1931-1944); en junio de 1944 y el de Jorge Ubico Castañeda en Guatemala, que desde 1931 gobernaba, tan sólo un mes después. En gran medida ambos gobiernos experimentaron el crecimiento de una fuerte oposición alimentada por los resultados de la Segunda Guerra y los intentos de restablecer un orden democrático en América Latina. Se podría establecer que los aires libertarios propulsados por las fuerzas aliadas se alinearon para reivindicar una serie de postulados que tenían como denominador común: el establecimiento de gobiernos democráticos a quienes poco tiempo después se les exigió una posición decididamente anticomunista ya en la coyuntura de la guerra fría.

Un proceso similar y contemporáneo experimentaba el exilio político republicano español desde su recomposición como oposición organizada aunque no unificada al franquismo. Desde el término de la guerra civil española, una de las tareas inmediatas consistía en el salvamento y salida de millares de

La Revista Estudios es editada por la Universidad de Costa Rica y se distribuye bajo una Licencia Creative Commons Atribución-NoComercial-CompartirIgual 3.0 Costa Rica. Para más información envíe un mensaje a revistaestudios.eeg@ucr.ac.cr. 
Revista Estudios, (38), 2019.

Junio 2019-Noviembre 2019

ISSN 1659-3316

Mejía Flores José Francisco

ciudadanos que simpatizaban o de plano participaban con el gobierno republicano.

Para ello gozaron de la solidaridad internacional, de redes académicas, culturales

e intelectuales y de organismos de ayuda creados ex profeso por su propio gobierno. Por eso durante el cuatrienio que comprende de 1939 a principios de 1943, el contenido político de la emigración política española se concentrará fundamentalmente en la organización de la salida y llegada de familias enteras, en la reconstrucción de los organismos políticos y sindicales, y en la ubicación e identificación de cuantos republicanos se hallaban dispersos por el mundo aunque principalmente en dos puntos neurálgicos: Francia y México. Sólo el resultado de la guerra internacional y el triunfo de las fuerzas soviéticas sobre las huestes de Hilter en la célebre batalla de Stalingrado en febrero de 1943 dieron la pauta para pensar y actuar sobre un visible derrocamiento del franquismo.

Con el resultado de la guerra, que presagiaba el triunfo aliado hacía 1944, el exilio político español no escapó a la creación y organización de cientos de organizaciones antifascistas en sus diferentes formatos: clubes, juntas oficiosas, movimientos de liberación, organizaciones independientes, etcétera, que hicieron su aparición desde inicios de la década de 1940 pero que formalmente existieron a partir de 1943 como precisamente sucedió con la creación de la Unión Democrática Centroamericana (UDC).

Este documento pretende articular el posicionamiento de la UDC con respecto a los acontecimientos de España, debido a que compartieron el espacio geográfico e ideológico con la causa de la República Española, las condenas al

\section{(c) (i) (2) (2)}

La Revista Estudios es editada por la Universidad de Costa Rica y se distribuye bajo una Licencia Creative Commons Atribución-NoComercial-CompartirIgual 3.0 Costa Rica. Para más información envíe un mensaje a revistaestudios.eeg@ucr.ac.cr. 
Revista Estudios, (38), 2019.

Junio 2019-Noviembre 2019

ISSN 1659-3316

Mejía Flores José Francisco

nazi fascismo y por extensión al franquismo que aún en esos momentos pensaba en establecer un proyecto cultural panhispánico bajo la egida del catolicismo pues se mostraba radicalmente anticomunista. Un vivo ejemplo de cómo el resultado de la guerra mundial, hacia principios de 1943, influía en el ánimo de muchas iniciativas para derrocar a sus gobiernos, nos remite a la formación de una gran cantidad de plataformas antifascistas en América Latina, constituyendo en México la principal tribuna de las consignas antifascistas en la órbita latinoamericana, porque recordemos que países como Brasil o Argentina, aunque se habían alineado con las Naciones Unidas, sus gobiernos se habían mostrado dubitativos en determinado momento, para conformar una alianza de alcance continental decididamente adversa al fascismo. Así, mientras la UDC se formó en la Ciudad de México el 3 de enero de 1943, dese finales de 1942 funcionaba una delegación en México de la Junta Suprema de Unificación Española, (JSUNE) de raigambre comunista y en noviembre de 1943 se formó la Junta Española de Liberación (JEL), que se disolvió en agosto de 1945, justo cuando se formó el gobierno republicano en el exilio, el 17 de agosto de 1945.

La UDC, por su parte, representaba los intereses y la ideología de un sector de la emigración política centroamericana que había establecido en México su centro de acción. Escritores, periodistas e intelectuales centroamericanos habían hecho de México su casa y quizá su segunda patria. El contexto de la guerra mundial no hizo sino reafirmar su ideario unionista, libertario, anti totalitario, anti nazi fascista y por extensión anti franquista. Por ejemplo, el periodista

\section{(c) (i) (2)}

La Revista Estudios es editada por la Universidad de Costa Rica y se distribuye bajo una Licencia Creative Commons Atribución-NoComercial-CompartirIgual 3.0 Costa Rica. Para más información envíe un mensaje a revistaestudios.eeg@ucr.ac.cr. 
Revista Estudios, (38), 2019.

Junio 2019-Noviembre 2019

ISSN 1659-3316

Mejía Flores José Francisco

hondureño Rafael Heliodoro Valle vivía en México desde la década de 1910 y se

había convertido en un referente del periodismo cultural con amplios contactos en

América Latina y España. Al mismo tiempo el escritor guatemalteco Luis Cardoza

y Aragón vivía en México desde 1936 y se había convertido en una autoridad en la

crítica del arte, amplio conocedor del muralismo mexicano. Cardoza desde su

trabajo en el diario oficial El Nacional, trabó una excelente amistad con escritores

republicanos españoles. Una situación similar vivía el escritor costarricense

Vicente Sáenz quien había experimentado un exilio en la Ciudad de México en la década de 1920 y en 1933 participó junto con Vicente Lombardo Toledano en la creación de la Universidad Obrera de México. Sáenz estuvo en la Guerra Civil Española como corresponsal, regresó a Costa Rica y en 1939 se estableció definitivamente en México convirtiéndose, en la órbita de los exiliados centroamericanos, en quien quizá mejor conocía los sucesos españoles pues publicó sus notas y apreciaciones periodísticas en un imperdible libro titulado España Heroíca.' Estos tres escritores se integraron a la UDC. Pero a ello se suma una larga lista de políticos, periodistas, académicos e intelectuales como Àngel Zúñiga Huete, Alfonso Guillén Zelaya, Raúl Cordero Amador, Rafael Alduvín, Claudia Lars, Clemente Marroquín Rojas y Jorge García Granados.

Esta iniciativa parte de una detallada revisión bibliográfica que se ha encargado de recopilar todos aquellos trabajos que traten el tema de las relaciones entre América Latina y España durante el franquismo y del impacto que tuvo la guerra civil española y el exilio republicano en la región. ii De la cual se

\section{(c) (i) (-)}

La Revista Estudios es editada por la Universidad de Costa Rica y se distribuye bajo una Licencia Creative Commons Atribución-NoComercial-CompartirIgual 3.0 Costa Rica. Para más información envíe un mensaje a revistaestudios.eeg@ucr.ac.cr. 
Revista Estudios, (38), 2019.

Junio 2019-Noviembre 2019

ISSN 1659-3316

Mejía Flores José Francisco

desprendió la valoración de que el impacto del exilio español en Centroamérica aún no se ha trabajado lo suficiente para escenarios como El Salvador, Honduras y Nicaragua, y se conocen avances significativos para escenarios como Guatemalaiii y Costa Rica $^{\mathrm{iv}}$. De manera que este artículo pretende contribuir al estudio de las relaciones de Centroamérica y España en el marco de la Segunda Guerra Mundial $^{\vee}$ y al papel de los exiliados centroamericanos que invariablemente se solidarizaban con la causa de la República Española desde la Ciudad de México en donde compartían espacios operativos y articulaban redes ideológicas que hacían de esta ciudad una activa capital del antifascismo desde América Latina. $^{\text {vi }}$

\section{El exilio centroamericano y la UDC}

Poco se conoce sobre el desarrollo del exilio centroamericano en México a partir de 1931 y hasta 1948, momento en que la Guerra Fría en el ámbito latinoamericano comienza a establecerse con más precisión ante las políticas anti comunistas del gobierno estadounidense. Autoras como Guadalupe Rodríguez de Ita, ${ }^{\text {vii }}$ Margarita Silva viii y Laura Morenoix, han abonado al terreno de la historiografía, mientras que otros autores como Mario Oliva, Iván Molina, David Díaz, Macarena Barahona y Marielos Aguilar han estudiado el papel de la política centroamericana de esos años enfocada principalmente al caso costarricense, a través de figuras políticas como Vicente Sáenz, Teodoro Picado, Rafael Ángel Calderón Guardía, Carlos Luis Fallas, Carmen Lyra, Manuel Mora Valverde,

\section{(c) (i)(2)}

La Revista Estudios es editada por la Universidad de Costa Rica y se distribuye bajo una Licencia Creative Commons Atribución-NoComercial-CompartirIgual 3.0 Costa Rica. Para más información envíe un mensaje a revistaestudios.eeg@ucr.ac.cr. 
Joaquín García Monge y José Figueres, entre los más destacados. Algunos de ellos vivieron exiliados en determinado momento en México.

En realidad quizá sigue haciendo falta un estudio que razone con más detalle sobre el papel del exilio centroamericano en México y su proyección hacia América Latina y El Caribe, porque los procesos políticos que se registraban en el istmo permitieron la planificación de proyectos oposicionistas y en determinadas circunstancias con un carácter unionista, libertario y anti totalitario como sucedió en el caso de la creación de la UDC.

El influjo de la guerra internacional en ese momento revivió con fuerza el espíritu unionista en el espectro centroamericano. Hacia 1922 el intelectual nicaragüense Salvador Mendieta había formado el Partido Unionista Centroamericano (PUCA), y desde ese entonces intelectuales como Vicente Sáenz habían participado en dicho proyecto. Por lo que la idea del unionismo en Sáenz jamás desapareció.

A ello habría que sumar que en el ámbito de la guerra mundial, la lucha se diversificó hacía el antifascismo y el anti totalitarismo mejor representado en los gobiernos de Alemania, Italia y España, mientras que América Latina fueron blanco de sus consignas Trujillo en República Dominicana, Anastasio Somoza en Nicaragua, Jorge Ubico en Guatemala, Tiburcio Carias en Honduras y Maximiliano Hernández Martínez en El Salvador Estas particularidades históricas propiciaron, por un lado, la formación en México de un colectivo de centroamericanos francos opositores a sus gobiernos, y, por otro, la interacción con otros exiliados que

\section{(c) (i) (2) (-)}

La Revista Estudios es editada por la Universidad de Costa Rica y se distribuye bajo una Licencia Creative Commons Atribución-NoComercial-Compartirlgual 3.0 Costa Rica. Para más información envíe un mensaje a revistaestudios.eeg@ucr.ac.cr. 
Revista Estudios, (38), 2019.

Junio 2019-Noviembre 2019

ISSN 1659-3316

Mejía Flores José Francisco

llegaban a México por una causa similar: el establecimiento, en sus países, de gobiernos dictatoriales entre los que destacaban los republicanos españoles, un colectivo germano parlantes; compuesto de alemanes, checos y austríacos, un minoritario grupo de italianos y hasta un representativo colectivo de franceses que en su mayor parte se adhirieron al movimiento liberacionista liderado por Charles De Gaulle.

Todo indica, según el estudio de Margarita Silva, que la UDC tuvo en la figura de Vicente Sáenz a uno de sus más activos protagonistas, pues el intelectual costarricense había trabado importantes vínculos con políticos e intelectuales mexicanos, latinoamericanos y desde luego con republicanos españoles. Uno de sus principales amigos fue Vicente Lombardo Toledano pues una década antes había sido miembro fundador de la Universidad Obrera de México. Sin embargo, no sólo Sáenz trabajó arduamente en la dirección que tomaba la UDC desde México, según el registro de su Comisión Ejecutiva una pléyade de periodistas, intelectuales y escritores provenientes de las naciones del istmo también se adhirieron al proyecto unionista. En ella participaban: Ricardo Alduvín (Honduras); Guillermo Alvarado (Honduras); Luis Cardoza y Aragón (Guatemala); Raúl Cordero Amador (Costarricense); Manuel Flores (Hondureño); Jorge García Granados (Guatemala); Alfonso Guillen Zelaya (Honduras); Humberto Herradora (Nicaragua); Claudia Lars (El Salvador); Juan José Laboriel (Honduras); José Asencio Menéndez (El Salvador); Juan José Meza (Nicaragua); Francisco Lino Osegueda (El Salvador); Concepción Palacios (Nicaragua); José

\section{(c) (i) (2) (2)}

La Revista Estudios es editada por la Universidad de Costa Rica y se distribuye bajo una Licencia Creative Commons Atribución-NoComercial-Compartirlgual 3.0 Costa Rica. Para más información envíe un mensaje a revistaestudios.eeg@ucr.ac.cr. 
Prado Romaña (Guatemala); Ángel Fuentes (Nicaragua); Maximiliano Tejeda

(Guatemala); Rafael Heliodoro Valle (Nicaragua); Francisco Zamora (Nicaragua);

Pedro José Zepeda (Nicaragua); y José Ángel Zúñiga Huete (Honduras). ${ }^{x i}$ Pocos

días después de su creación El Popular, diario de la Confederación de Trabajadores de México informaba a sus lectores los propósitos fundamentales de la UDC. Sin embargo, será el propio Sáenz quien explicó con pormenores la relación entre el proyecto unionista y lo que estaba sucediendo en el contexto de la guerra:

"La Carta del Atlántico, las conquistas de la Revolución Mexicana, la legislación obrera, La Oficina Internacional del Trabajo, las declaraciones del vicepresidente de los Estados Unidos y del ex candidato republicano Wendell Wilkie, lo que el propio presidente Roosevelt ha podido realizar en la Federación Anglosajona, con su justiciera política social en beneficio de las mayorías: todo eso -para que los pazguatos (sic) y los reaccionarios no empiecen a hablar de comunismo- forma el programa mínimo de la Unión Democrática Centroamericana, como forma igualmente el programa mínimo del Frente Nacional Unionista de El Salvador". xii

En efecto, la UDC no era la única agrupación centroamericana que buscaba la planificación de un proyecto estrictamente político de carácter anti dictatorial. También existió una Unión de Guatemaltecos anti ubiquistas y los nicaragüenses formaron el Comité Antisomosista de México en el que participaban exiliados de otras nacionalidades. ${ }^{\text {xii }}$ En todo caso, según Margarita Silva y como bien lo reafirma Sáenz, la formación de un Frente Unionista Salvadoreño dio la pauta para la creación de la UDC en la Ciudad de México. En muy poco tiempo la UDC logró la simpatía de una buena parte de la sociedad mexicana y en conjunto con otras organizaciones de exiliados participaron en una serie de actos de reivindicación

\section{(C) $(\Theta \odot \odot$}

La Revista Estudios es editada por la Universidad de Costa Rica y se distribuye bajo una Licencia Creative Commons Atribución-NoComercial-CompartirIgual 3.0 Costa Rica. Para más información envíe un mensaje a revistaestudios.eeg@ucr.ac.cr. 
Revista Estudios, (38), 2019.

Junio 2019-Noviembre 2019

ISSN 1659-3316

Mejía Flores José Francisco

anti fascista de gran calado. Sus alcances trascendieron al ámbito de su lucha: es

decir; la unión de Centroamérica. Para ello, publicaron un boletín Centroamérica en pie, y procuraron un sello editorial "UDC", que publicó estudios o recopiló colaboraciones que el propio Sáenz entregó a los diarios de circulación nacional en México.

Todo indica que al regresar algunos de sus principales animadores, con el derrocamiento de los gobiernos de Guatemala y El Salvador en 1944, la UDC, aminoró sus actividades a partir de 1946. Con ello, su participación siguió enfocada a reafirmar su postura progresista y sobre todo a continuar con su labor editorial. Vicente Sáenz Rojas ${ }^{\text {xiv }}$ siguió en México y continuó un largo trabajo periodístico en los diarios mexicanos. Luis Cardoza y Aragón ${ }^{x v}$ regresó de Guatemala a partir de los sucesos que ocasionaron el derrocamiento de Jacobo Arbenz en 1954 y Rafael Heliodoro Valle ${ }^{x v i}$, fue Embajador de Honduras en Estados Unidos, y, entre otros cargos, fue un connotado profesor de historia de la Universidad Nacional Autónoma de México, falleció en 1959.

\section{La UDC y su afinidad con la República Española 1943-1945}

Diversos autores señalan que la reactivación del exilio político español se

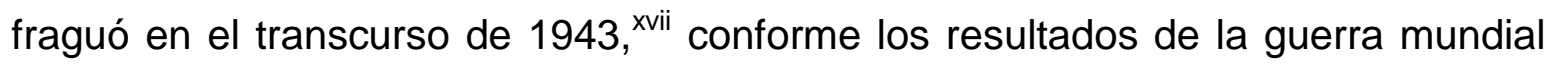
establecían paradigmas que tenían que ver fundamentalmente con una nueva política internacional que iba demandando el enfrentamiento de las dos potencias triunfadoras. Una de ellas en el hemisferio occidental, los Estados Unidos de

\section{(c) (i) (2) (2)}

La Revista Estudios es editada por la Universidad de Costa Rica y se distribuye bajo una Licencia Creative Commons Atribución-NoComercial-CompartirIgual 3.0 Costa Rica. Para más información envíe un mensaje a revistaestudios.eeg@ucr.ac.cr. 
América y, otra, en el oriental, la Unión de Repúblicas Socialistas Soviéticas. Ello demandó inmediatamente la proyección de una estrategia anti franquista que tuviera la posibilidad de vislumbrar el futuro de España, sin Franco en el poder.

A partir de ese momento la lucha por la restauración democrática en España, tendrá un resultado negativo a partir de 1946. Franco se mantuvo en el poder, y paulatinamente fue aceptado en el concierto internacional de países miembros de la ONU y en el contexto latinoamericano fue reconocido por todas las naciones con excepción de México, Guatemala, Venezuela y Panamá. En América Latina, las condiciones políticas y los cambios que experimentaban Guatemala, Venezuela y Panamá, incidieron en el reconocimiento del gobierno republicano español, sin embargo, Guatemala concluyó su ensayo revolucionario en 1954, en Venezuela fue derrocado en octubre de 1948 el gobierno de Rómulo Gallegos y en Panamá, concluyó la etapa de Adolfo Jiménez Brim quien gobernó entre el 15 de junio de 1945 y el 1 de octubre de 1948. Ello dio la pauta para dar un golpe de timón y esos tres países reconocieron, después de sus cambios de régimen, al franquismo español. Sólo México se mantuvo firme y nunca reconoció al gobierno de Franco. En todo caso para Miguel Ángel Yuste, la desunión del bando republicano y el nulo reconocimiento que Estados Unidos, Gran Bretaña y la Unión Soviética $^{\text {xiii }}$ dieron al gobierno en el exilio incidieron en la sobrevivencia del franquismo a pesar de su aislamiento hasta $1950 .^{\text {xix }}$

Una muestra altamente representativa de lo anteriormente señalado tiene que ver precisamente con la formación de dos plataformas anti franquistas que

\section{(c) (i) (9) (2)}

La Revista Estudios es editada por la Universidad de Costa Rica y se distribuye bajo una Licencia Creative Commons Atribución-NoComercial-CompartirIgual 3.0 Costa Rica. Para más información envíe un mensaje a revistaestudios.eeg@ucr.ac.cr. 
enfrentaban cada vez más al bando republicano. Ambas tuvieron el carácter de juntas oficiosas y se distinguieron por propagar dos estrategias diferentes sobre cómo enfrentar el futuro de España después de la guerra mundial. La Ciudad de México fue escenario de sus debates y enfrentamientos entre la fecha de su creación y su desaparición, es decir, entre 1943 y 1946. Me refiero a la Junta Española de Liberación (JEL) y la Junta Suprema de Unificación de España (JSUNE). ${ }^{x x}$

La historia de la JSUNE esta intrínsecamente ligada a la participación de la Unión Soviética en la guerra contra el nazi fascismo. Los cuadros que la integraron formaban parte del Partido Comunista de España (PCE), del Partido Socialista Unificado de Cataluña (PSUC) y de sus Juventudes Socialistas Unificadas (JSU); y también contó con miembros del Partido Socialista Obrero Español (PSOE) y del sindicato Unión General de Trabajadores (UGT). Otro sector del PSOE y de la UGT, el mayoritario, participó en la JEL.

El rompimiento del pacto germano-soviético en junio de 1941, ocasionó la formación de una plataforma comunista internacional que incidió inmediatamente en el caso español. Los cuadros comunistas hicieron un llamamiento que incluía a todos aquellos antifranquistas que quisiesen integrar una amplia plataforma por lo que invitaba incluso a los monárquicos a un proyecto que denominaron Unión Nacional Española (UNE). En su concepto la guerra dejó de ser una lucha inter imperialista que protagonizaban Gran Bretaña y Francia contra Alemania e Italia. A partir de ese momento Estados Unidos y la URSS reforzaban el frente aliado 
contra Hitler y Mussolini. La estrategia de la UNE, siguió su curso y en 1942 cambió su denominación por la de Unión Democrática Española (UDE). Un año después en septiembre de 1943 quedó finalmente constituida como Junta Suprema de Unificación Española. Esta Junta contó con la solidaridad en México, del Partido Comunista Mexicano, de la Confederación de Trabajadores de México, de una Federación de Organismos de Ayuda a los Republicanos Españoles (FOARE), y de líderes políticos como el propio Vicente Lombardo Toledano, Víctor Manuel Villaseñor, Narciso Bassols y José Mancisidor, quienes lograron animar y crear una Sociedad de Amigos de la URSS, mejor conocida como la SAURSS. En muy poco tiempo celebraron con gran entusiasmo la reapertura de relaciones entre México y la URSS, en noviembre de 1942, y tuvieron en la Embajada soviética en México y en su titular Constantino Umamsky, fallecido en un trágico accidente de aviación a principios de 1945, a uno de sus mejores interlocutores. ${ }^{\text {xi }}$ Diarios y revistas como El Popular de la CTM y Futuro de la Universidad Obrera de México, o La voz de México, del Partido Comunista de México, dieron espacios a líderes de la JSUNE en su afrenta contra Franco.

Otra alternativa para los exiliados españoles se concentró en la labor de la Junta Española de Liberación (JEL), formada en noviembre de 1943 en la Ciudad de México y que alcanzó su mayor éxito en las conferencias de San Francisco en la primavera de 1945 cuando por interposición del gobierno mexicano, logró que la recién creada ONU condenará al régimen establecido en España desde abril de 1939, "con ayuda de los países del Eje". La JEL la animaron los partidos

La Revista Estudios es editada por la Universidad de Costa Rica y se distribuye bajo una Licencia Creative Commons Atribución-NoComercial-CompartirIgual 3.0 Costa Rica. Para más información envíe un mensaje a 
Revista Estudios, (38), 2019.

Junio 2019-Noviembre 2019

ISSN 1659-3316

Mejía Flores José Francisco

republicanos liberales del exilio, Izquierda Republicana y Unión Republicana y contó con el beneplácito de los sectores reformistas del PSOE y la UGT, quienes creían que la participación de los comunistas en el proceso político español, implicaba la animadversión de Estados Unidos y Gran Bretaña. Creían firmemente en la restauración de un sistema republicano formalmente plasmado en su constitución de 1931. Sus principales líderes fueron en el presidente de las Cortes, Diego Martínez Barrio e Indalecio Prieto, líder del PSOE y ministro durante la República y la Guerra. La JEL quedó formalmente disuelta el 31 de agosto de 1945, tan sólo trece días después de la formación del gobierno republicano, pues consideraron que su misión histórica había concluido.

Ahora bien esta introducción nos ayuda a considerar que la JSUNE y la JEL no sólo compartían con la UDC un espacio de exilio; la Ciudad de México, sino que a pesar de sus diferencias, los tres proyectos, se identificaban por condenar al fascismo, al nazismo y al franquismo. Sin embargo, por la documentación consultada se puede afirmar que el vínculo de la UDC y de sus principales propulsores fue más fuerte con la JSUNE que con la JEL. Una muestra singular de ello, es el homenaje que el 13 de febrero de 1943, el círculo socialista "Jaime Vera", allegado a las posturas de Negrín, en ese momento saludado por los sectores comunistas de la emigración hispana, ofrecieron a Vicente Sáenz, en la Peña Montañesa de la Ciudad de México. El motivo: su conocimiento y solidaridad con la República ante el conflicto español. Al acto asistieron no sólo los principales líderes de la PCE y el PSUC, sino también los españoles ligados al proyecto de

\section{(c) (i) (2) (2)}

La Revista Estudios es editada por la Universidad de Costa Rica y se distribuye bajo una Licencia Creative Commons Atribución-NoComercial-CompartirIgual 3.0 Costa Rica. Para más información envíe un mensaje a revistaestudios.eeg@ucr.ac.cr. 
Revista Estudios, (38), 2019.

Junio 2019-Noviembre 2019

ISSN 1659-3316

Mejía Flores José Francisco

Negrín desde el PSOE y la UGT, tales como Amaro del Rosal, Ramón González

Peña y Ramón Lamoneda, quienes al mismo tiempo animaban el Círculo "Jaime Vera", rival del Círculo "Pablo Iglesias" allegado a la JEL y al grupo prietista del socialismo.

Esta apreciación no es menor si consideramos que las divisiones del exilio español en México, también se dieron en otras esferas de acción. Por ejemplo, Negrín, y sus principales colaboradores habían creado el Comité Técnico de Ayuda a los Republicanos Españoles (CTARE) con sede en París y una sección en México, denominada Servicio de Emigración a los Republicanos Españoles (SERE) quien tuvo en el doctor José Puche Álvarez, a su presidente. Entre otras actividades el SERE, logró atender y auxiliar a los primeros refugiados españoles hasta 1940 en que se agotaron sus recursos. Uno de sus principales logros fue la creación del Instituto "Luis Vives", que hasta la fecha existe como entidad educativa de prestigio en la Ciudad de México. El distanciamiento entre Negrín y Prieto, tuvo otro escenario de acción cuando en julio de 1939, la Diputación Permanente de las Cortes, autorizó que se creara la Junta de Ayuda a los Republicanos Españoles (JARE), con los recursos del gobierno republicano que fueron recogidos por Prieto, en marzo de 1939 y que habían sido enviados por Negrín a México, en los momentos finales de la guerra. La JARE auxilió a los exiliados que llegaron entre 1941 y 1942 y entre otras funciones fundó un proyecto educativo rival conocido como "El Colegio Madrid" que también cuenta con una gran tradición educativa en la Ciudad de México. Los recursos de la JARE, fueron

\section{(c) (i) (2) (2)}

La Revista Estudios es editada por la Universidad de Costa Rica y se distribuye bajo una Licencia Creative Commons Atribución-NoComercial-CompartirIgual 3.0 Costa Rica. Para más información envíe un mensaje a revistaestudios.eeg@ucr.ac.cr. 
Revista Estudios, (38), 2019.

Junio 2019-Noviembre 2019

ISSN 1659-3316

Mejía Flores José Francisco

intervenidos por el gobierno mexicano a finales de 1942, y administrados por el

Ejecutivo mexicano, hasta septiembre de 1945, cuando fueron entregados a José

Giral, elegido como Jefe del gobierno republicano en el exilio unos días antes. xxii

Vicente Sáenz, había logrado cultivar una gran amistad con los republicanos y la República, desde su etapa de corresponsal de guerra en España. Sus impresiones fueron recogidas en un libro titulado España Heroica, que se convirtió en un documento de propaganda republicana que había logrado captar la atención y la simpatía de buena parte de la intelectualidad latinoamericana. Su fascinación por dar seguimiento a los procesos políticos europeos y en especial a los españoles, puede seguirse en sus colaboraciones a la prensa, más tarde recogidos en libros, algunos de ellos bajo el sello editorial de la UDC. Para el homenaje que los republicanos españoles le ofrecieron el 13 de febrero de 1943, Sáenz preparó las siguientes palabras: "Soy un escritor político, entiendo la política como la ciencia de la justicia social y la misión del intelectual consiste en orientar los problemas colectivos al servicio del pueblo". ${ }^{\text {xiii }}$

Homenajear a Sáenz a principios de 1943, tan sólo un mes después de la formación de la UDC en la Ciudad de México en una coyuntura que exigía la planeación de una estrategia anti franquista eficaz con todos los elementos que conformaban el bloque aliado era consustancial a las luchas que identificaban a los exiliados españoles con los centroamericanos. Según El Popular, en la mesa de honor al escritor costarricense estuvieron: "el licenciado Luis Sánchez Pontón, el licenciado Ramón Gómez Esqueda, los ex ministros republicanos Antonio Velao

\section{(c) (i) (2)}

La Revista Estudios es editada por la Universidad de Costa Rica y se distribuye bajo una Licencia Creative Commons Atribución-NoComercial-CompartirIgual 3.0 Costa Rica. Para más información envíe un mensaje a revistaestudios.eeg@ucr.ac.cr. 
y Ramón González Peña, el doctor José Puche Álvarez, ex rector de la Universidad de Valencia, el doctor Manuel Márquez, ex rector de la Universidad de Madrid, el licenciado Luciano Castillo, jefe del Partido Socialista del Perú, el Ministro de Costa Rica en México, Carlos Jinesta, y el licenciado García Granados, al frente de la Unión Democrática Centroamericana".

Otro elemento que llama poderosamente la atención para identificar el posicionamiento de la UDC con la causa española, tiene relación con la participación de otro de sus destacados integrantes: el escritor y periodista Rafael Heliodoro Valle, quien también se había ocupado de la guerra española y había conseguido la amistad de escritores, diplomáticos, políticos, científicos y artistas españoles. Heliodoro Valle, se había convertido en un referente del periodismo cultural en México y con la llegada de muchos republicanos en 1939 su interés por la cusa anti franquista persistió. La lucha en España a partir del 18 de julio de 1936 impactó profundamente a una gran mayoría de los intelectuales latinoamericanos que desde sus espacios de opinión manifestaron su postura en torno a los sucesos. Heliodoro Valle y Vicente Sáenz, cultivaban una amistad que puede ser seguida a través de la correspondencia revisada en el Fondo "Heliodoro Valle" que resguarda la UNAM, y en todo momento se manifestaron en contra de la insurrección en España. Desde sus ideas y sus letras apoyaron a la República. Por ejemplo, Heliodoro Valle, en 1937, le solicitaba a Gilberto Bosques, entonces director de El Nacional, que publicaran una entrevista que Sáenz, logró hacerle a Manuel Azaña, presidente de la II República:

\section{(c) (i) (2)}

La Revista Estudios es editada por la Universidad de Costa Rica y se distribuye bajo una Licencia Creative Commons Atribución-NoComercial-CompartirIgual 3.0 Costa Rica. Para más información envíe un mensaje a revistaestudios.eeg@ucr.ac.cr. 
"Muy estimado amigo: el periodista costarricense Don Vicente Sáenz, a quien tú conoces seguramente, pues vivió algún tiempo aquí, me acaba de enviar de Valencia la entrevista que ha celebrado con el presidente Azaña y me indica que la ponga a disposición de El Nacional. Si fuera posible que ustedes pagaran esa colaboración, estaría muy bien, pero si no, de todas maneras el señor Sáenz la pone a sus órdenes para que la utilicen, ya que al mismo tiempo aparecerá en la prensa europea". xxiv

Según revela la compilación de las entrevistas que Heliodoro Valle, hizo para la revista universitaria, Universidad. Mensual de Cultura Popular 1936-1938, coordinado por Raquel Mosqueda Rivera, y publicada por el Instituto de Investigaciones Filológicas de la UNAM, ${ }^{x x v}$ el escritor hondureño entrevistó a actores importantes del gobierno y la intelectualidad republicana española. Destacan las entrevistas a Cipriano Rivas Cherif, a León Felipe, a Marcelino Domingo, a José Pijoan, a José Moreno Villa y a Fernando de los Ríos, quien en ese momento era el embajador en Estados Unidos. Además en la entrevista que logró hacer a Martín Luis Guzmán, le consultó sobre su trabajo como colaborador cercano de Azaña, durante su estancia en España, en donde el escritor mexicano escribió su célebre obra La sombra del caudillo.

Tan grande pudo ser el interés que despertaban en Heliodoro Valle, los sucesos españoles, que en determinado momento cuando entrevistó a De los Ríos, escribió: "Puedo afirmarle -le digo- que en México hay ahora un interés al segundo por lo que está sucediendo en España. Creemos que es la hora de España, en que se cruzan los destinos. La hora de América, también."

\section{(c) (i) (2)}

La Revista Estudios es editada por la Universidad de Costa Rica y se distribuye bajo una Licencia Creative Commons Atribución-NoComercial-CompartirIgual 3.0 Costa Rica. Para más información envíe un mensaje a revistaestudios.eeg@ucr.ac.cr. 
Para finalizar, no menos trascendente es lo que escribió al respecto el escritor guatemalteco, Luis Cardoza y Aragón, integrante también de la UDC y exiliado en México desde 1936, a donde se llegó a incorporar a El Nacional. Cardoza, había cultivado una gran amistad con Federico García Lorca, desde su estancia en Europa. Además a la llegada de los exiliados españoles, confirmó su amistad con muchos de los periodistas, redactores y traductores que trabajaron para el diario oficial del Partido de la Revolución Mexicana. Cardoza en su novela autobiográfica El río, novelas de caballería, ${ }^{x x v i}$ revela en diferentes pasajes su amistad y compromiso con la causa republicana. En la investigación de Arturo Taracena, sobre las relaciones entre Guatemala y la República Española (19441954), se ubican con detalle las labores diplomáticas que Cardoza, emprendió para lograr la llegada a Guatemala de un grupo de republicanos españoles, inspirada en un proyecto de inmigración que impulsó el gobierno de Juan José Arévalo. ${ }^{\text {xxvii } U n a ~ m u e s t r a ~ d e ~ s u ~ p a r t i c i p a c i o ́ n ~ c o m o ~ s e g u r o ~ i n t e r l o c u t o r ~ y ~ a m i g o ~ d e ~}$ los republicanos españoles en Guatemala es la última carta que le escribiera el diplomático guatemalteco Enrique Muñoz Meany, quien en ese momento se encontraba al frente de la Embajada en París, en donde tan sólo dos meses después murió. Muñoz Meany solicitaba a Cardoza, su intermediación para poder colocar al escritor español Fernando Revuelta en algún trabajo allí:

\section{cc) (1) (2)}

La Revista Estudios es editada por la Universidad de Costa Rica y se distribuye bajo una Licencia Creative Commons Atribución-NoComercial-Compartirlgual 3.0 Costa Rica. Para más información envíe un mensaje a 
Muy querido Luis: Va mi saludo afectuoso con estas líneas que te entregará su portador, don Fernando F. Revuelta, escritor español republicano, que después de luchar duramente en la guerra civil española, de pasar largo tiempo en prisión y de sufrir las inclemencias del exilio en Francia, se ha decidido a buscar mejor ambiente en nuestro país. Te lo recomiendo muy especialmente. El señor Revuelta fue amigo muy cercano y compañero de prisión del gran poeta Miguel Hernández. Aquí ha trabajado en toda clase de labores intelectuales y hasta materiales, para lograr la subsistencia de su familia. Nos ha prestado una valiosa ayuda en labores de publicidad. Él es uno de los animadores y de los autores de La Documentation Francaise, dedicado a Guatemala, que tú conoces. Es demócrata, siguiendo una línea ideológica de gran honestidad, y creo que en Guatemala podrá ayudarnos en muchas tareas importantes, sobre todo en periodismo y radiofonía, a más de otros proyectos que él tiene y que te expondrá. Espero que puedas ayudarle conectándole con nuestros amigos. ${ }^{\text {xxviii }}$

Estos tres ejemplos que tienen que ver con la participación de Sáenz, Helidoro Valle y Cardoza y Aragón, integrantes de la UDC, con respecto a España, son sólo un botón de muestra que indican cómo para la organización centroamericana, la lucha antifranquista formó parte de su prontuario de demandas y consignas contra lo que, en ese momento, se llegó a denominar como la "barbarie nazi". Las nuevas condiciones políticas que experimentaron Guatemala y El Salvador hacia 1945, sin duda incidieron en el funcionamiento de la UDC. A partir de ese momento la hegemonía estadounidense en América Latina, tendrá un nuevo estigma: la lucha contra el comunismo en el escenario de la guerra fría.

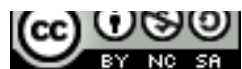

La Revista Estudios es editada por la Universidad de Costa Rica y se distribuye bajo una Licencia Creative Commons Atribución-NoComercial-CompartirIgual 3.0 Costa Rica. Para más información envíe un mensaje a 


\section{VALORACIÓN FINAL}

Poco se ha trabajado sobre la llegada del exilio centroamericano a México entre las décadas de 1930 y 1940 y los avances más significativos en la materia corresponden a los casos de Guatemala, Nicaragua y Costa Rica. ${ }^{x x i x}$ En ese sentido desconocíamos por completo cómo se pudieron imbricar las actividades de la Unión Democrática Centroamericana en México con la causa de la República Española, a pesar de que no sólo compartían el espacio geográfico sino también el ideológico, es decir, la lucha antifascista. Según se desprende de las actividades, correspondencia y trayectoria de tres prominentes integrantes de la UDC, Sáenz, Heliodoro Valle y Cardoza y Aragón, la causa de la República Española, tocó su sensibilidad intelectual y personal desde la insurrección patrocinada por el nazi fascismo en España.

El caso que más llama la atención y que ofrece aún pistas más precisas para ir armando el rompecabezas, es el de Vicente Sáenz, quien mantuvo una proximidad con los sectores negrinistas de la emigración española e incluso se puede localizar parte de su correspondencia con Amaro del Rosal, líder la UGT pro negrinista. ${ }^{x x x}$ Es probable que esto influyera en la cercanía que la UDC, mantuvo con el proyecto de la JSUNE, y con el respaldo que daban hacia 1945 a la candidatura de Juan Negrín, como jefe del gobierno republicano en el exilio y que en detrimento de ellos (la JSUNE) no sucedió.

\section{(c) (i) (-)}

La Revista Estudios es editada por la Universidad de Costa Rica y se distribuye bajo una Licencia Creative Commons Atribución-NoComercial-CompartirIgual 3.0 Costa Rica. Para más información envíe un mensaje a 
Revista Estudios, (38), 2019.

Junio 2019-Noviembre 2019

ISSN 1659-3316

Mejía Flores José Francisco

\section{Referencias}

\section{Archivo}

\section{Fondo "Rafael Heliodoro Valle" Biblioteca Nacional, UNAM}

Hemerografía

\section{El Popular}

\section{Futuro}

\section{Bibliografía}

Angosto, P. L. (2009) La República en México. Con plomo en las alas (1939-1945), Sevilla: Renacimiento

Cardoza y Aragón, L. (1985) El río. Novelas de caballería. México: FCE.

Galindo, J. G. (1983) "Las relaciones entre México y la Unión Soviética durante la Segunda Guerra Mundial”, México: El Colegio de México/Centro de Relaciones Internacionales, tesis de licenciatura.

Herrerín, Á. (2007) El dinero del exilio. Indalecio Prieto y las pugnas de posguerra (1939-1947) Madrid: Siglo XXI.

Mateos, A. (2009), La batalla de México. Final de la guerra civil y ayuda a los refugiados. Madrid: Alianza editorial.

Mejía, J.F. (2014), "El exilio republicano español en América Latina: 75 años de historiografía y política (1939-2014)" en Adalberto Santana (coordinador), Diálogo intecultural latinoamericano, México, UNAM-CIALC, serie coloquios, pp. 257-272.

Mejía, J.F. (2015), "Una aproximación historiográfica al estudio del exilio español en América Latina a través de su impacto en México, el Caribe y Centroamérica" en Mari Carmen Serra Puche, José Francisco Mejía Flores y Carlos Sola Ayape (coordinadores), Política y sociedad en el exilio republicano español, México: UNAM-CIALC, (colección Exilio Iberoamericano), pp. 119-130.

Mejía, J.F. (2019), "Consensos y disensos sobre el exilio español en México, en el contexto de la Segunda Guerra Mundial” en Rubén Torres Martínez (editor), Conflictos y clivajes. Una visión multidisciplinaria, Mérida: UNAM/CEPHCIS, serie Ensayos núm. 22, pp. 179-199.

\section{(C) $(\triangle 0$}

La Revista Estudios es editada por la Universidad de Costa Rica y se distribuye bajo una Licencia Creative Commons Atribución-NoComercial-CompartirIgual 3.0 Costa Rica. Para más información envíe un mensaje a 
Mejía, J.F. y Moreno, L. (2015), "El exilio costarricense en México en la década de 1940" en Cuadernos Americanos, México: UNAM/CIALC, pp. 51-73.

Melgar, R. (2018), Redes e imaginario del exilio en América Latina 1934-1940, México: UNAM-CIALC, colección América Latina, lecturas imprescindibles.

Moreno, L. (2015), Exilio nicaragüense en México (1937-1947). México: UNAMCIALC, (Colección Exilio Iberoamericano), Número, 4.

Moreno, L. (2016) "Vigilar al exilio centroamericano. Informes confidenciales sobre su presencia en México, 1930-1940" en Antropología. Boletín oficial del Instituto Nacional de Antropología e Historia, mueva época, diciembre 2016, número 101, pp. 77-94.

Oliva, M. (2008) Los intelectuales y las letras centroamericanas sobre la Guerra Civil Española, México: UNAM-CIALC.

Portero, F. (1989) Franco aislado: la cuestión española 1945-1950, Madrid: Aguilar.

Rodríguez, G. (2011), "Exilio, activismo y vigilancia: el caso de los guatemaltecos antiubiquistas (1931-1944)" en Delia Salazar y Gabriela Pulido (coordinadoras), De agentes, rumores e informes confidenciales. La inteligencia políticas y los extranjeros en la primera mitad del siglo XX". México: INAH.

Rosal, A. (1986) Catálogo de los archivos donados por Amaro del Rosal Díaz, elaborado por Beatriz García Paz y Carmen Motilva Martí, Madrid: Fundación Pablo Iglesias.

Sáenz, V. (2013) España Heroica. San José: EUNA-UCR-UNED, Colección Vicente Sáenz, Tomo VI.

Silva, M. (2013), "La Unión Democrática Centroamericana en la lucha de Vicente Sáenz contra las tiranías y los déspotas del istmo, 1942-1926", en Gilberto Lopes (editor), Tras las huellas de Vicente Sáenz. A los 50 años de su muerte, San José: EUNA-UCR-UNED, Colección Vicente Sáenz, Tomo I. pp. 19-49.

Taracena, A. (2017), Guatemala, la República Española y el gobierno vasco en el exilio (1944-1954). Mérida: UNAM-CEPCHIS/EI Colegio de Michoacán.

Taracena, A. (2015) "Guatemala y el reconocimiento de la República española en el exilio" en Mari Carmen Serra Puche, José Francisco Mejía Flores y Carlos Sola

\section{(c) (i) (2)}

La Revista Estudios es editada por la Universidad de Costa Rica y se distribuye bajo una Licencia Creative Commons Atribución-NoComercial-CompartirIgual 3.0 Costa Rica. Para más información envíe un mensaje a 
Ayepe (coordinadores), Política y sociedad en el exilio republicano español, México: UNAM/CIALC, Colección Exilio Iberoamericano, núm. 2, pp. 105-118.

Velázquez, A. (2014) Empresas y finanzas: los organismos de ayuda a los republicanos españoles en México (1939-1949). México: El Colegio de México.

Velázquez, A. El placer de corresponder. Correspondencia entre Cardoza y Aragón, Muñoz Meany y Arriola (1945-1951), prólogo, selección y notas de Arturo Taracena, Arely Mendoza y Julio Pinto Soria, Guatemala: Universidad de San Carlos, pp. 387-388.

Yuste de Paz, M. A. (2005), La I/ República en el exilio en los inicios de la guerra fría (1945-1951), Madrid: Fundación Universitaria Española.

\footnotetext{
'Véase Sáenz Rojas, Vicente, (2013) España Heroica, San José: EUNA-UCR-UNED, Colección Vicente Sáenz, Tomo VI.

ii Véase Mejía Flores, José Francisco (2014), "El exilio republicano español en América Latina: 75 años de historiografía y política (1939-2014)" en Adalberto Santana (coordinador), Diálogo intecultural latinoamericano, México, UNAM-CIALC, serie coloquios, pp. 257-272; Mejía Flores, José Francisco (2015), "Una aproximación historiográfica al estudio del exilio español en América Latina a través de su impacto en México, el Caribe y Centroamérica" en Mari Carmen Serra Puche, José Francisco Mejía Flores y Carlos Sola Ayape (coordinadores), Política y sociedad en el exilio republicano español, México: UNAM-CIALC, (colección Exilio Iberoamericano), pp. 119-130.

iii Para revisar al estudio más actualizado y completo véase Taracena Arriola, Arturo, (2017), Guatemala, la República Española y el gobierno vasco en el exilio (1944-1954), Mérida: UNAMCEPCHIS/EI Colegio de Michoacán.

iv Una visión general del impacto de la guerra civil en las letras centroamericanas en Oliva Medina, Mario, (2008) Los intelectuales y las letras centroamericanas sobre la Guerra Civil Española, México: UNAM-CIALC.

${ }^{\vee}$ Este texto se enmarca en un proyecto más amplio que desarrolló en el CIALC y que lleva por título "Centroamérica y España: política, acción diplomática y exilio, 1939-1947".

vi Un espléndido estudio sobre las redes del exilio latinoamericano en México en Melgar Bao, Ricardo, (2018), Redes e imaginario del exilio en América Latina 1934-1940, México, UNAMCIALC, colección América Latina, lecturas imprescindibles.

vii Véase Rodríguez de Ita, Guadalupe (2011), "Exilio, activismo y vigilancia: el caso de los guatemaltecos antiubiquistas (1931-1944)" en Delia Salazar y Gabriela Pulido (coordinadoras), De agentes, rumores e informes confidenciales. La inteligencia políticas y los extranjeros en la primera mitad del siglo XX", México: INAH.

viii Véase Silva, Margarita, (2013), "La Unión Democrática Centroamericana en la lucha de Vicente Sáenz contra las tiranías y los déspotas del istmo, 1942-1926", en Gilberto Lopes (editor), Tras las huellas de Vicente Sáenz. A los 50 años de su muerte, San José: EUNA-UCR-UNED, Colección Vicente Sáenz, Tomo I. pp. 19-49.

${ }^{i x}$ Véase Moreno Rodríguez, Laura Beatriz, (2015), Exilio nicaragüense en México (1937-1947), México: UNAM-CIALC, (Colección Exilio Iberoamericano), Número, 4.
}

\section{(ब) (ब०}

La Revista Estudios es editada por la Universidad de Costa Rica y se distribuye bajo una Licencia Creative Commons Atribución-NoComercial-Compartirlgual 3.0 Costa Rica. Para más información envíe un mensaje a 
${ }^{x}$ La oposición a estos dictadores dio pie a la formación poco después de la Legión Caribe, que se formó en México en 1947 y demandó la caída de dictadores como Trujillo en Dominicana, Batista en Cuba, Somoza en Nicaragua y Carias en Honduras, debido a que con excepción de Costa Rica todos estos países eran gobernados por dictadores de conducta militar. Sin embargo, de la mano de la Legión el gobierno de Costa Rica, de Teodoro Picado fue destituido en abril de 1948 por un comando militar legionario al frente del cual se encontraba, José Figueres Ferrer.

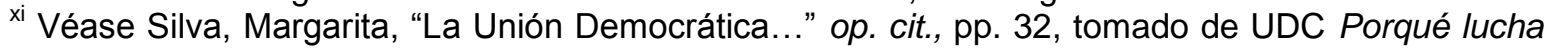
Centroamérica, p. 1.

xii Vicente Sáenz "Unión Democrática Centroamericana", en El Popular, 8 de enero de 1943.

xiii Véase Moreno Rodríguez, Laura Beatriz, (2016) "Vigilar al exilio centroamericano. Informes confidenciales sobre su presencia en México, 1930-1940" en Antropología. Boletín oficial del Instituto Nacional de Antropología e Historia, mueva época, diciembre 2016, número 101, pp. 7794.

xiv Vicente Sáenz Rojas, (San José, Costa Rica, 30 de septiembre de 1896- Ciudad de México, 28 de marzo de 1963).

${ }^{x v}$ Luis Cardoza y Aragón (Antigua, Guatemala, 21 de junio de 1901-Ciudad de México, 4 de septiembre de 1992).

xvi Rafael Heliodoro Valle (Tegucigalpa, Honduras, 3 de julio de 1891-Ciudad de México, 29 de julio de 1959).

xvii Véase Angosto Vélez, Pedro Luis, (2009), La República en México. Con plomo en las alas (1939-1945), Sevilla: Renacimiento; Mateos López, Abdón (2009), La batalla de México. Final de la guerra civil y ayuda a los refugiados, Madrid: Alianza editorial; y Yuste de Paz, Miguel Ángel, (2005), La Il República en el exilio en los inicios de la guerra fría (1945-1951), Madrid: Fundación Universitaria Española.

xviii Para Yuste de Paz "el fracaso republicano no se debió a la falta de ayuda de las potencias democráticas, mejor dicho, no fue únicamente la ausencia de dicho apoyo. Tras la falta de interés internacional por España, aparecía también la penosa desunión de las fuerzas anti franquistas que desanimaban cualquier intento de apoyar una alternativa a Franco. Las potencias democráticas no vieron nunca en las instituciones republicanas en el exilio una verdadera representación del pueblo español", en La II República en el exilio en los inicios de la guerra fría.... Op. cit., p. 15.

xix Véase Portero, Florentino (1989), Franco aislado: la cuestión española 1945-1950, Madrid: Aguilar.

${ }^{\mathrm{xx}}$ Una muestra de los enfrentamientos de estas dos opciones anti franquistas desde México en Mejía Flores, José Francisco (2019), "Consensos y disensos sobre el exilio español en México, en el contexto de la Segunda Guerra Mundial" en Rubén Torres Martínez (editor), Conflictos y clivajes. Una visión multidisciplinaria, Mérida: UNAM/CEPHCIS, serie Ensayos núm. 22, pp. 179-199.

xxi Véase Galindo González, Juan Gustavo, (1983), "Las relaciones entre México y la Unión Soviética durante la Segunda Guerra Mundial", México: El Colegio de México/Centro de Relaciones Internacionales, tesis de licenciatura.

xxii Para un seguimiento más detallado de las organizaciones de ayuda republicanas se recomienda: Herrerín López, Ángel, (2007), El dinero del exilio. Indalecio Prieto y las pugnas de posguerra (1939-1947), Madrid: Siglo XXI; y Velázquez Hernández, Aurelio, (2014), Empresas y finanzas: los organismos de ayuda a los republicanos españoles en México (1939-1949), México: El Colegio de México.

xxiii "Fue agasajado por los republicanos el sr. Vicente Sáenz. Declaró que el Falangismo Español es más peligroso en América que el propio nazi fascismo", en El Popular, 15 de febrero de 1943.

xxiv "Rafael Heliodoro Valle a Gilberto Bosques" 24 de agosto de 1937. Fondo "Heliodoro Valle", Biblioteca Nacional de México, UNAM.

xxv Véase (2015), Edición anotada de las entrevistas de Rafael Heliodoro Valle en la revista Universidad. Mensual de Cultura Popular 1936-1938, coordinación general, edición y estudio preliminar, Raquel Mosqueda Rivera, México: UNAM/Instituto de Investigaciones Filológicas.

\section{(@) $\odot \odot$}

La Revista Estudios es editada por la Universidad de Costa Rica y se distribuye bajo una Licencia Creative Commons Atribución-NoComercial-Compartirlgual 3.0 Costa Rica. Para más información envíe un mensaje a revistaestudios.eeg@ucr.ac.cr. 
xxvi Véase Cardoza y Aragón, Luis (1985), El río. Novelas de caballería, México: FCE.

xxvii Véase Taracena Arriola, Arturo, (2015) "Guatemala y el reconocimiento de la República española en el exilio" en Mari Carmen Serra Puche, José Francisco Mejía Flores y Carlos Sola Ayepe (coordinadores), Política y sociedad en el exilio republicano español, México: UNAM/CIALC, Colección Exilio Iberoamericano, núm. 2, pp. 105-118

xxviii "Enrique Muñoz Meany a Luis Cardoza y Aragón", París, 27 de octubre de 1951, en (2004), El placer de corresponder. Correspondencia entre Cardoza y Aragón, Muñoz Meany y Arriola (19451951), prólogo, selección y notas de Arturo Taracena, Arely Mendoza y Julio Pinto Soria, Guatemala: Universidad de San Carlos, pp. 387-388.

xxix Véase Mejía Flores, José Francisco y Laura Beatriz Moreno Rodríguez (2015), "El exilio costarricense en México en la década de 1940" en Cuadernos Americanos, México: UNAM/CIALC, pp. 51-73.

xxx Véase (1986) Catálogo de los archivos donados por Amaro del Rosal Díaz, elaborado por Beatriz García Paz y Carmen Motilva Martí, Madrid: Fundación Pablo Iglesias.

La Revista Estudios es editada por la Universidad de Costa Rica y se distribuye bajo una Licencia Creative Commons Atribución-NoComercial-Compartirlgual 3.0 Costa Rica. Para más información envíe un mensaje a revistaestudios.eeg@ucr.ac.cr. 